Article

\title{
Bone Regeneration Using a Three-Dimensional Hexahedron Channeled BCP Block Combined with Bone Morphogenic Protein-2 in Rat Calvarial Defects
}

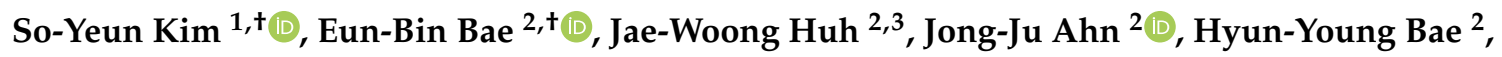 \\ Won-Tak Cho ${ }^{2}$ (I) and Jung-Bo Huh ${ }^{2, *}$ \\ 1 Department of Prosthodontics, Biomedical Research Institute, Pusan National University Hospital, \\ Busan 49241, Korea \\ 2 Department of Prosthodontics, Dental Research Institute, Dental and Life Science Institute, BK21 PLUS \\ Project, School of Dentistry, Pusan National University, Yangsan 50612, Korea \\ 3 Seroun Dental Clinic, Suyeong-ro, Nam-gu, Busan 48445, Korea \\ * Correspondence: neoplasia96@hanmail.net; Tel.: +82-10-8007-9099; Fax: +82-55-360-5134 \\ + These authors contributed equally to this work.
}

Received: 3 July 2019; Accepted: 29 July 2019; Published: 31 July 2019

\begin{abstract}
It is important to obtain sufficient bone mass before implant placement on alveolar bone, and synthetic bone such as biphasic calcium phosphate $(\mathrm{BCP})$ has been studied to secure this. This study used a BCP block bone with a specific structure of the three-dimensional (3D) hexahedron channel and coating with recombinant human bone morphogenetic protein-2 (rhBMP-2) impregnated carboxymethyl cellulose $(\mathrm{CMC})$ was used to examine the enhancement of bone regeneration of this biomaterial in rat calvarial defect. After the preparation of critical-size calvarial defects in fifteen rats, defects were divided into three groups and were implanted with the assigned specimen $(\mathrm{n}=5)$ : Boneplant (untreated 3D hexahedron channeled BCP block), Boneplant/CMC (3D hexahedron channeled BCP block coated with CMC), and Boneplant/CMC/BMP (3D hexahedron channeled $\mathrm{BCP}$ block coated with CMC containing rhBMP-2). After 4 weeks, the volumetric, histologic, and histometric analyses were conducted to measure the newly formed bone. Histologically, defects in the Boneplant/CMC/BMP group were almost completely filled with new bone compared to the Boneplant and Boneplant/CMC groups. The new bone volume $(P<0.05)$ and area $(P<0.001)$ in the Boneplant/CMC/BMP group $(20.12 \% \pm 2.17,33.79 \% \pm 3.66)$ were much greater than those in the Boneplant $(10.77 \% \pm 4.8,16.48 \% \pm 9.11)$ and Boneplant/CMC $(10.72 \% \pm 3.29,16.57 \% \pm 8.94)$ groups, respectively. In conclusion, the 3D hexahedron channeled BCP block adapted rhBMP-2 with carrier CMC showed high possibility as an effective bone graft material.
\end{abstract}

Keywords: biphasic calcium phosphate; bone regeneration; bone substitute; recombinant human bone morphogenetic protein-2; carboxymethyl cellulose

\section{Introduction}

In dental clinics, implant procedures have become routine, and most often, and almost uniquely, the most limiting factor is when a large amount of bone is lost. If enough bone is available, the difficulty of the implant procedure will be greatly reduced [1]. In reality, however, the bone volume is often small-scale due to various complications, such as periodontitis, trauma, and alveolar bone resorption due to a long edentulous period. What is required as an ideal bone graft material for this purpose is a scaffold that promotes new bone formation, acts as a pathway for bone-forming material, can be optimally degraded and replaced with new bone, and has sufficient strength and stability $[2,3]$. Examples of reconstructed alveolar bone include using a bone graft or guided bone regeneration [4], 
using frozen and radiation sterilized allogenic bone grafting [5], use of graft materials from animals or synthetic production [6], recent use of marine collagen and substitutes [7], and so on. Among them, until now, the most promising method for gaining the alveolar bone has been ideally presented with an autologous bone graft with osteogenic potential. However, there are concerns about the availability and morbidity of the donor, difficulty in shaping, and complexity of the surgery [8,9]. On the other hand, the application of allografts or xenografts is also limited by the drawbacks of immune reaction complications, disease transmission, and the absence of osteogenetic properties that could lead to bone resorption and nonunion $[10,11]$.

New bone graft materials such as 3D scaffolds have been recently studied in the dental field as alternatives to overcome the weak points of previous graft materials. As an alternative to bone grafts of sufficient size and diversiform shape, synthetic bone grafts are becoming increasingly popular because they are capable of sufficient production and have no immune reactions [12-15]. Block structures instead of powders contribute to stability by themselves. Depending on the size and shape, as well as the architecture and geometry design, they may promote the clustering of stem cells or osteoprogenitor cells and induce them to function as attachment elements within the scaffold [16]. The internal porous structure helps the circulation of tissue ingrowth, body fluids, and nutrients, and the 3D environmental factors, such as pore size and orientation, also influence the tissue regeneration broadly [17]. At this time, aligned pores are more advantageous for cell migration than irregular pores [18].

Meanwhile, biphasic calcium phosphate (BCP), a synthetic bone graft material, is a mixture of stable phase hydroxyapatite (HA) and soluble phase beta tricalcium phosphate ( $\beta$-TCP) that is widely used because of its biocompatible, osteoconductive, bioactive, safe, and predictable properties $[19,20]$. $\mathrm{BCP}$ ceramic is considered a promising scaffold for use with tissue engineering strategies for large bone augmentation. In dentistry, $\mathrm{BCP}$ bioceramic is also recommended as an alternative or supplementary material for autogenous bone [21]. The biomaterial should have a clinically manageable macrostructure, and a microstructure that induces cell adhesion and proliferation [22]. Because their chemical properties, size, and shape can be easily controlled, they have become a multipurpose matrix for bone formation and development [19].

However, to date, the osteoinductivity of biomaterials is still limited and shows a large difference compared to the one with rhBMP-2 [23]. The recombinant human bone morphogenetic protein-2 (rhBMP-2), an osteoinductive growth factor, is sometimes used in the dental field [24,25]. It has a high bone regeneration capability, which differentiates mesenchymal stem cells (MSCs), transforms pre-osteoblasts into osteoblasts, and acts as a trigger for migration of osteoblasts [26,27]. This leads to early stage osteogenic differentiation of stem cells and osteoprogenitor cells to initiate bone formation [28,29]. Meanwhile, the uncontrolled release of rhBMP-2 causes numerous complications, such as heterotopic ossification, osteolysis, or cancer [30,31]. Despite these problems, rhBMP-2 has outstanding effects on bone defect reconstruction and implant osseointegration acceleration, so research is continuing into developing an effective delivery system for its release without adverse effects. [8,32]. A carrier maintains the release at the local site for the time required to induce bone regeneration [8]. A number of delivery systems composed of various materials have been studied for controlled sustained release of rhBMP-2 [33]. Carboxymethyl cellulose (CMC), which is used as a carrier in this study due to its non-toxicity, biodegradability, and hydrophilic characteristics, is a polysaccharide additive used recently in various industries [34-38]. CMC itself has the ability to contribute directly to the synthesis process of calcium phosphate and can be an effective template for biomimetic mineralization. In studies evaluating CMC as a carrier for rhBMP-2, the results showed that alkaline phosphatase activity of fibroblast cells was increased when rhBMP-2 and CMC were used separately, but CMC combined with rhBMP-2 exhibited much better effects [39,40]. By adding CMC to recombinant human osteogenic protein, the quality of union, total histologic appearance, handling characteristics, and stability are reported to be improved in a previous study [41]. According to Yoo et al. [42], in micro-computed tomography and tissue morphometry analysis, $\mathrm{BCP}$ with cross-linked $\mathrm{CMC}$ promoted new bone formation and increased new bone area ratio. In addition to maintaining the graft volume, $\mathrm{CMC}$ has 
been shown to promote bone metabolism, resulting in the formation of thick new bone around the graft materials in $\mathrm{BCP}$ mixed with cross-linked CMC.

The 3D scaffold synthetic block bone can be made with the desired structure and porosity, and can contain the desired biological materials [43]. Pae et al. [44] reported favorable osteogenetic activity of a 3D hexahedron channeled BCP block bone, the same material with used in this study. In comparison with the particle bone, it showed unremarkable new bone formation similar to the experimental group. This block bone is three-dimensionally connected with a tubule with a concave inner surface, made in line with regularity, and has a porosity of $95 \%$. Even when broken, due to the structural characteristics, it was not completely flawed and had the strength to maintain the volume. Three factors affecting the osteoinduction of biomaterials are chemical composition, macrostructure, and surface structure, and this graft material used in this study was expected to meet these requirements [45]. Another previous study that used this 3D hexahedron channeled synthetic bone block obtained favorable but not particularly high amounts of new bone volume in a rabbit calvarial defect model [44]. Therefore, in addition to the volume maintenance ability of this scaffold, we planned to gain more new bone through delivering the CMC and rhBMP-2, and develop a better new bone graft material. Therefore, using this 3D block bone graft material, in this study, we compared the bone formation capacity of in vivo rat calvarial defect model by combining CMC and rhBMP-2 to increase the bone regeneration ability of this 3D hexahedron channeled synthetic BCP block bone.

\section{Materials and Methods}

\subsection{Preparation of 3D Hexahedron Channeled Synthetic Block Bone}

All the specimens of 3D Hexahedron Channeled synthetic block bone were supplied (BoneplantTM, Ezekiel, Chungchung-Namdo, Korea) after sterilization using gamma irradiation. The 3D hexahedron channeled bone block was made of BCP microporous ceramics, with a mixture of $60 \% \mathrm{HA}$ and $40 \%$ $\beta$-TCP. The pore size of the disc-shaped bone block (diameter: $8 \mathrm{~mm}$, thickness: $2 \mathrm{~mm}$ ) was $400-700 \mu \mathrm{m}$ with $95 \%$ porosity (Figure 1). Prior to the animal experiment, the bone blocks were coated with $100 \mu \mathrm{L}$ of CMC (1.5\%, CowellMedi, Busan, Korea) or CMC containing 5 ug of rhBMP-2 (CowellMedi, Busan, Korea) in a completely sterile laboratory $[39,46]$. The low-level sonication was performed to uniformly coat CMC on the Boneplant surface. The experimental groups of this study were as below:

- Boneplant group: Untreated 3D hexahedron channeled BCP block;

- Boneplant/CMC group: 3D Hexahedron channeled BCP block coated with CMC;

- Boneplant/CMC/BMP group: 3D Hexahedron channeled BCP block coated with CMC containing rhBMP-2.
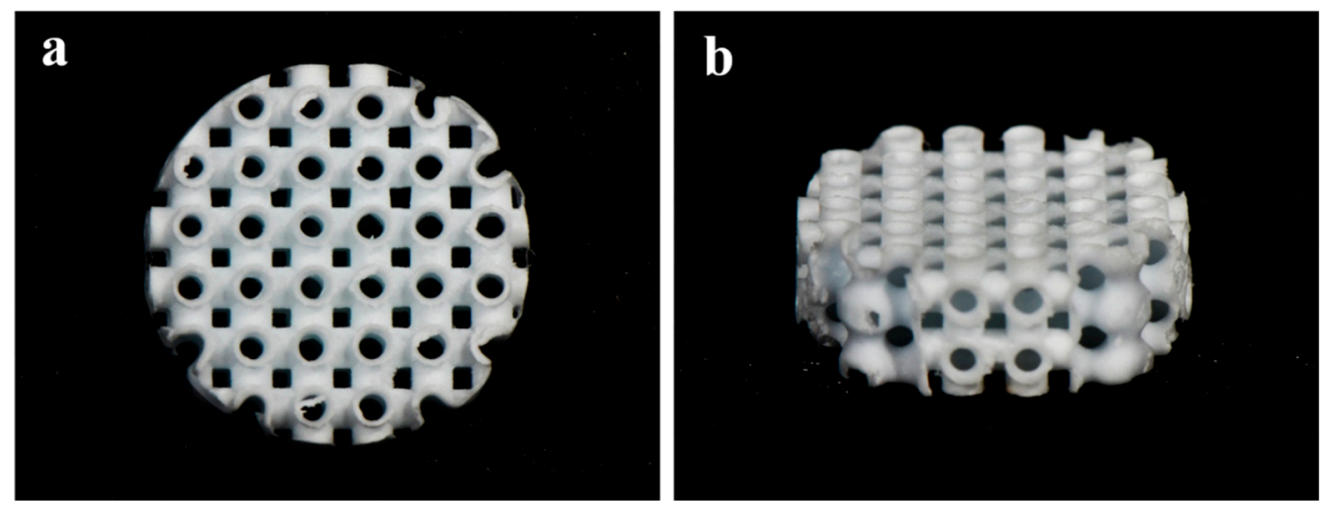

Figure 1. The images of BCP block bone with a 3D hexahedron channel. (a) Top view; (b) top-side view. 


\subsection{Scanning Electron Microscope Surface Analysis}

The specimens were observed using a Field Emission Scanning Electron Microscope (FE-SEM, S-4700, Hitachi, Tokyo, Japan) to assess morphologies of surface microstructures at magnifications of $\times 40, \times 250$, and $\times 1000$. The samples of each group were coated with platinum in ion sputter (E1010, HITACHI, Tokyo, Japan) and were observed using FE-SEM at accelerating voltage of $5 \mathrm{kV}$.

\subsection{In Vivo Animal Study}

\subsubsection{Experimental Animals}

Fifteen 12-week-old male Sprague-Dawley rats (5 per group) (Koatech, Pyeongtaek, Korea) weighing 250-300 g were used for this animal experiment. The animals adapted for at least 7 days before surgery and were caged individually with rodent pellets and water supplied ad-libitum. Animal management and surgical procedures were performed at the Pusan National University Laboratory Animal Resource Center and all the experiments followed routines approved by the Institutional Animal Care and Use Committee of Pusan National University (PNU-2018-2101).

\subsubsection{Surgical Procedures}

All the rats were anesthetized by general intramuscular injection of a mixture $(0.1 \mathrm{~mL} / 10 \mathrm{~g})$ of Tiletamine-zolazepam (Zoletil50, Virbac Korea, Seoul, Korea) and xylazine (Rompun lnj, Bayer Korea, Seoul, Korea) during the surgical procedures (Figure 2). The surgical sites were clearly shaved and scrubbed with Betadine ${ }^{\circledR}$ (povidone-iodine) for disinfection. The local anesthesia was applied using lidocaine (2\% Lidocaine $\mathrm{HCl}$ and Epinephrine Injection (1:100,000), Yuhan, Seoul, Korea). After making a sagittal incision across the middle of the cranium, the full-thickness flap was elevated to expose the calvarial bone. A critical-sized circular bony defect ( $8 \mathrm{~mm}$ in diameter) was created in the middle of the cranium using a saline-cooled trephine bur (Osung, Kimpo, Korea). Each defect was randomly implanted with an assigned bone block, and covered with a membrane $(10 \times 10 \mathrm{~mm}$, collagen membrane, GENOSS, Suwon, Korea). The skin and periosteum were respectively closed using absorbable sutures (4-0, Vicryl ${ }^{\circledR}$, Ethicon, NJ, USA). After 4 weeks, all if the rats were sacrificed by $\mathrm{CO}_{2}$ asphyxiation and the surgical sites with surrounding bone were carefully harvested. The obtained tissue samples were placed in 10\% neutral-buffered formalin (Sigma Aldrich, St. Louis, MO, USA) for 14 days.
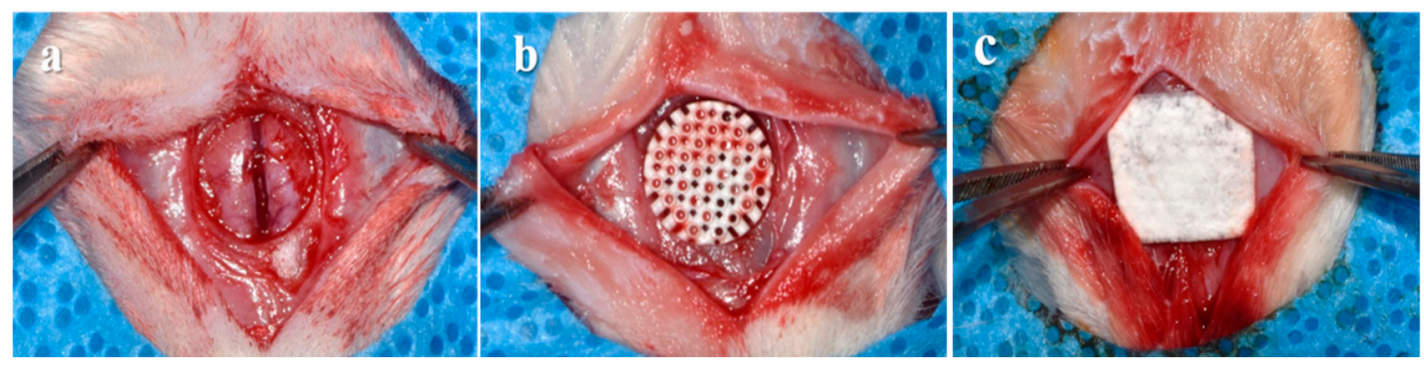

Figure 2. Surgical procedures of this animal experiment. (a) Bone defect formation on the cranium.

(b) Implantation of randomized block bone. (c) Placement of collagen membrane.

\subsubsection{Micro-Computed Tomography $(\mu \mathrm{CT})$ Analysis}

To measure the new bone volume within the defect area, the specimens were imaged by micro-computed tomography (SMX-90CT, Shimadzu, Kyoto, Japan) at $90 \mathrm{kV}$, at an intensity of $109 \mu \mathrm{A}$. The region of interest (ROI) was set equal to bony defect size (diameter of $8 \mathrm{~mm}$, height of $1.5 \mathrm{~mm}$ ) (Figure 3). The images distinguished mineralized bone, soft tissues, and scaffold by adjusting the threshold. The percentages of new bone volume were calculated by customized program corded by cording software (MATLAB 2018a, MathWorks, Natick, MA, USA). 


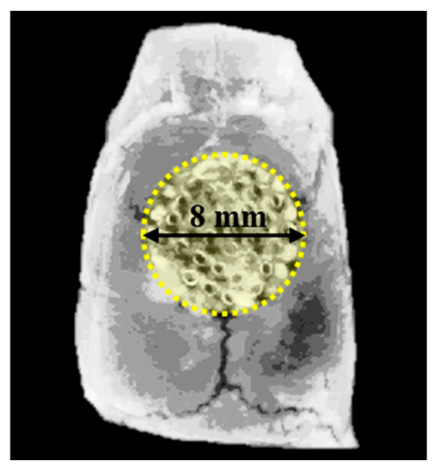

Figure 3. Region of interest (ROI) for micro-computed tomography $(\mu \mathrm{CT})$ analysis.

\subsubsection{Histologic and Histometric Procedures}

The harvested tissue samples were sequentially dehydrated with ethanol (70, 80, 90, and $100 \%$ ) and infiltrated with embedding methylacrylate-based resin (Technovit 7200 VLC, Heraeus Kulzer, Dormagen, Germany) and then hardened in an ultraviolet polymerization unit (EXAKT 520, Exakt-Apparatebau, Norderstedt, Germany). The final tissue slides with a thickness of $30 \mu \mathrm{m}$ were prepared from initial sections with $400 \mu \mathrm{m}$ thickness by cutting and grinding procedures using a microtome (KULZER EXAKT 300, Exakt-Apparatebau, Norderstedt, Germany) and grinding machine (KULZER EXAKT 400CS, Exakt-Apparatebau, Norderstedt, Germany). After staining the specimens with hematoxylin and eosin $(\mathrm{H} \& \mathrm{E})$ solution, all of the sections were photographed using a microscope (BX51, Olympus, Tokyo, Japan) with a digital CCD camera (Polaroid, MA, USA) For histometic analysis, the newly formed bones within defects were measured using an i-solution image analysis program (IMT, Daejeon, Korea) by a single investigator (Figure 4).
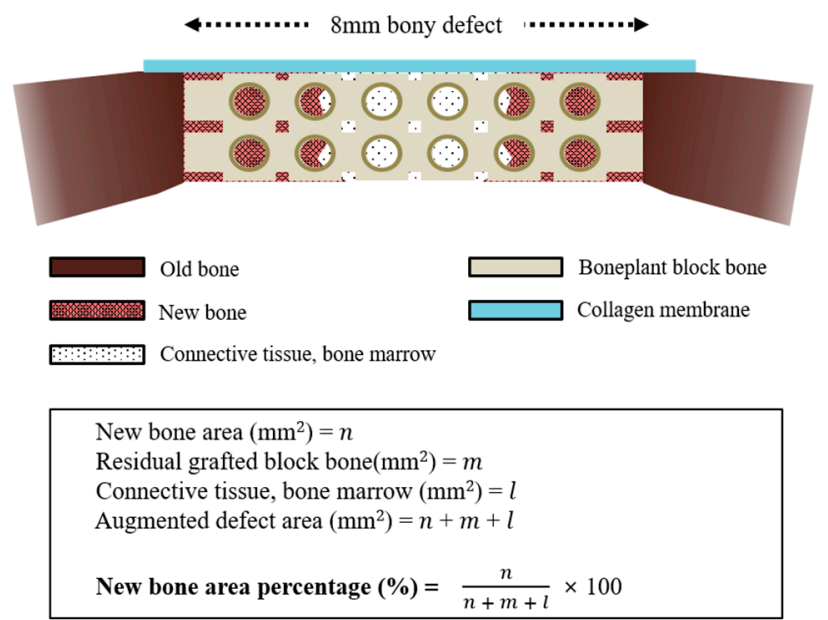

Figure 4. Schematic design for histometric analysis.

\subsection{Statistical Analysis}

Resulting data of each analysis are expressed as mean \pm standard deviation (SD). The in vivo results were analyzed by Kruskal-Wallis test with post-hoc Mann-Whitney test using statistical program (SPSS 25.0, SPSS, IL, USA). P-values $<0.05$ were considered statistically significant. 


\section{Results}

\subsection{Observations of Surface Morphology}

SEM analysis was used to examine the surface morphologies of Boneplant group and CMC coated groups (Boneplant/CMC and Boneplant/CMC/BMP group). Boneplants showed the 3D hexahedron channel (pore size of 400-700 $\mu \mathrm{m}$; Figure 5a,b). The rough surfaces were observed in the Boneplant group via aggregation of BCP particles (Figure 5c,e). In CMC coated groups, smooth surface were observed covered with CMC compared to the Boneplant group (Figure 5d,f).
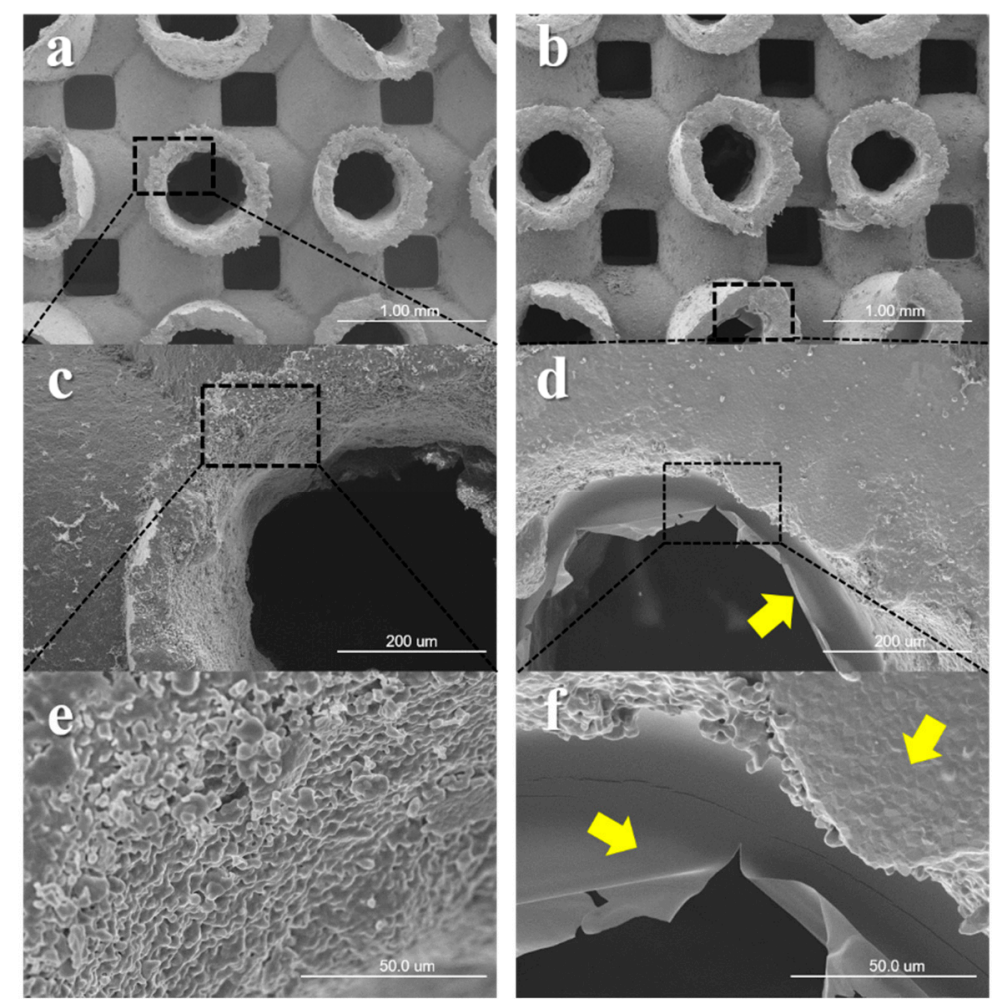

Figure 5. Captured images using scanning electron microscopy. (a,c,e) Boneplant group. (b,d,f) CMC coated groups, Boneplant/CMC, and Boneplant/CMC/BMP group. Yellow arrow: coated CMC on Boneplant surfaces [Original magnifications: $\times 40(\mathbf{a}, \mathbf{b}) \times 250(\mathbf{c}, \mathbf{d})$, and $\times 1000(\mathbf{e}, \mathbf{f})]$.

\subsection{In Vivo Animal Study}

\subsubsection{Clinical Findings}

All of the animals survived during the healing periods without adverse effects, such as infection, inflammation, and specimen exposure at surgical sites.

\subsubsection{Volumetric Findings}

The volumetric results of new bone in the Boneplant, Boneplant/CMC, and Boneplant/CMC/BMP groups were $10.77 \% \pm 4.87,10.72 \% \pm 3.29$, and $20.12 \% \pm 2.17$, respectively (Table 1, Figure $6 \mathrm{~g}$ ). The newly formed bone was detected between 3D channel pores, especially in the Boneplant/CMC/BMP group (Figure 6a-f). The Boneplant/CMC/BMP groups showed higher new bone volume than the others $(P<0.05)$. However, there was no significant difference between Boneplant and Boneplant/CMC groups $(P>0.05)$. 
Table 1. New bone volume within regions of interest ( $n=5$ per group).

\begin{tabular}{lcccc}
\hline & Groups & Mean & SD & P-Value \\
\hline \multirow{3}{*}{ New Bone Volume (\%) } & Boneplant & 10.77 & 4.87 & \\
& Boneplant/CMC & 10.72 & 3.29 & 0.013 * \\
& Boneplant/CMC/BMP & 20.12 & 2.17 & \\
\hline
\end{tabular}

The symbol * indicates statistical significance $(P<0.05)$.

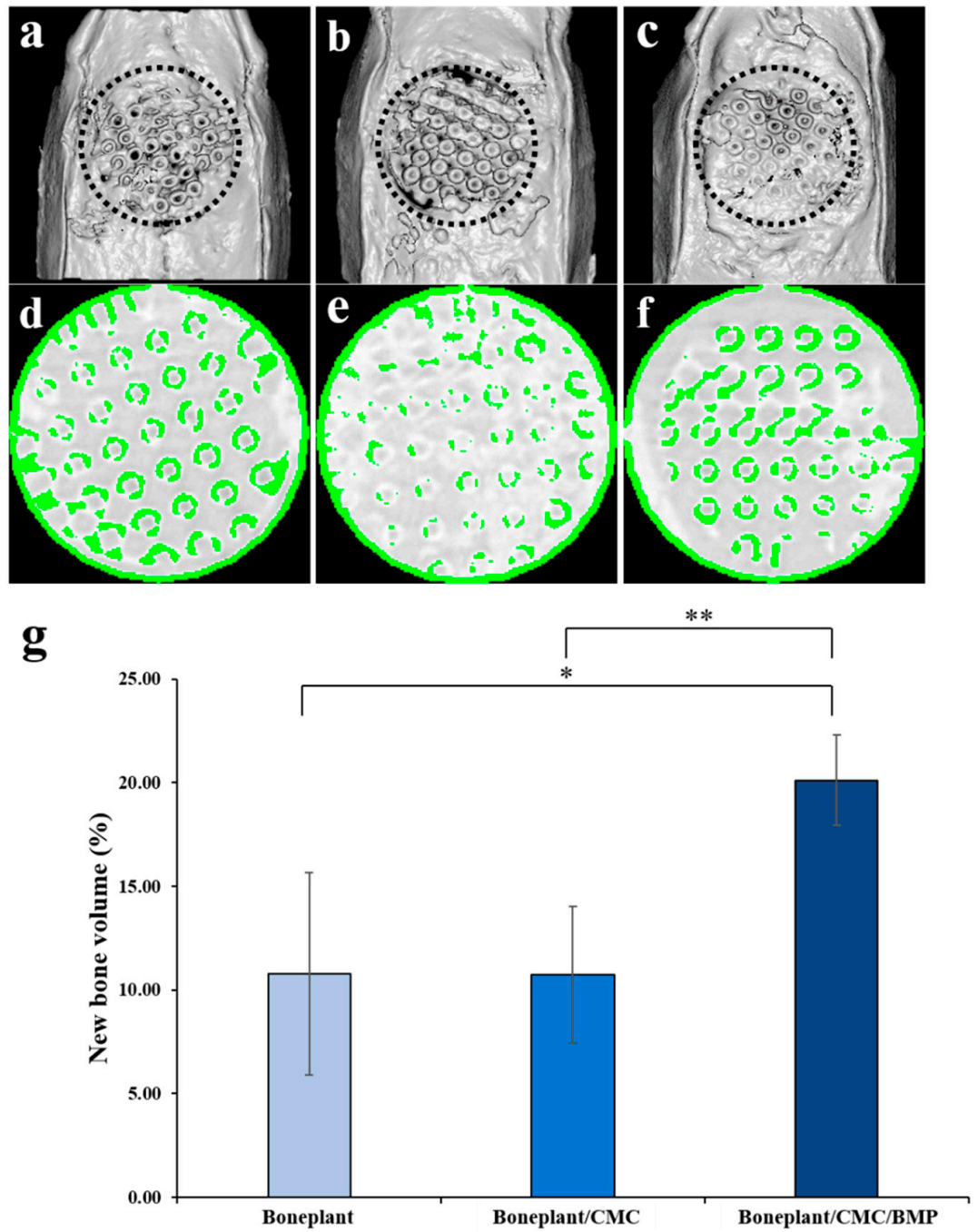

Figure 6. Micro-computed tomography $(\mu \mathrm{CT})$ findings. (a-f) Obtained $\mu \mathrm{CT}$ images of each group. (a,d) Boneplant; (b,e) Boneplant/CMC; (c,f) Boneplant/CMC/BMP groups. (a-c) 3D-reconstructed $\mu \mathrm{CT}$ images. (d-f) colored $\mu \mathrm{CT}$ images. Green colored area: newly formed bone. Gray colored area: grafted block bone. (g) New bone volume within region of interest. The symbol * indicates statistical significance $(P<0.05)$. The symbol ${ }^{* *}$ indicates statistical significance $(P<0.01)$.

\subsubsection{Histological Findings}

The histological abnormal findings such as inflammatory response were not observed in any tissue samples, and implanted bone graft materials were not collapsed and showed good space maintenance in bony defects (Figure 7). In all three groups, the newly regenerated bones infiltrated into the pores of the 3D hexahedron channel structure. In Boneplant and Boneplant/CMC groups, bone marrow and connective tissues were detected around the new bone. The defects of the Boneplant/CMC/BMP group were almost filled with new bone. 


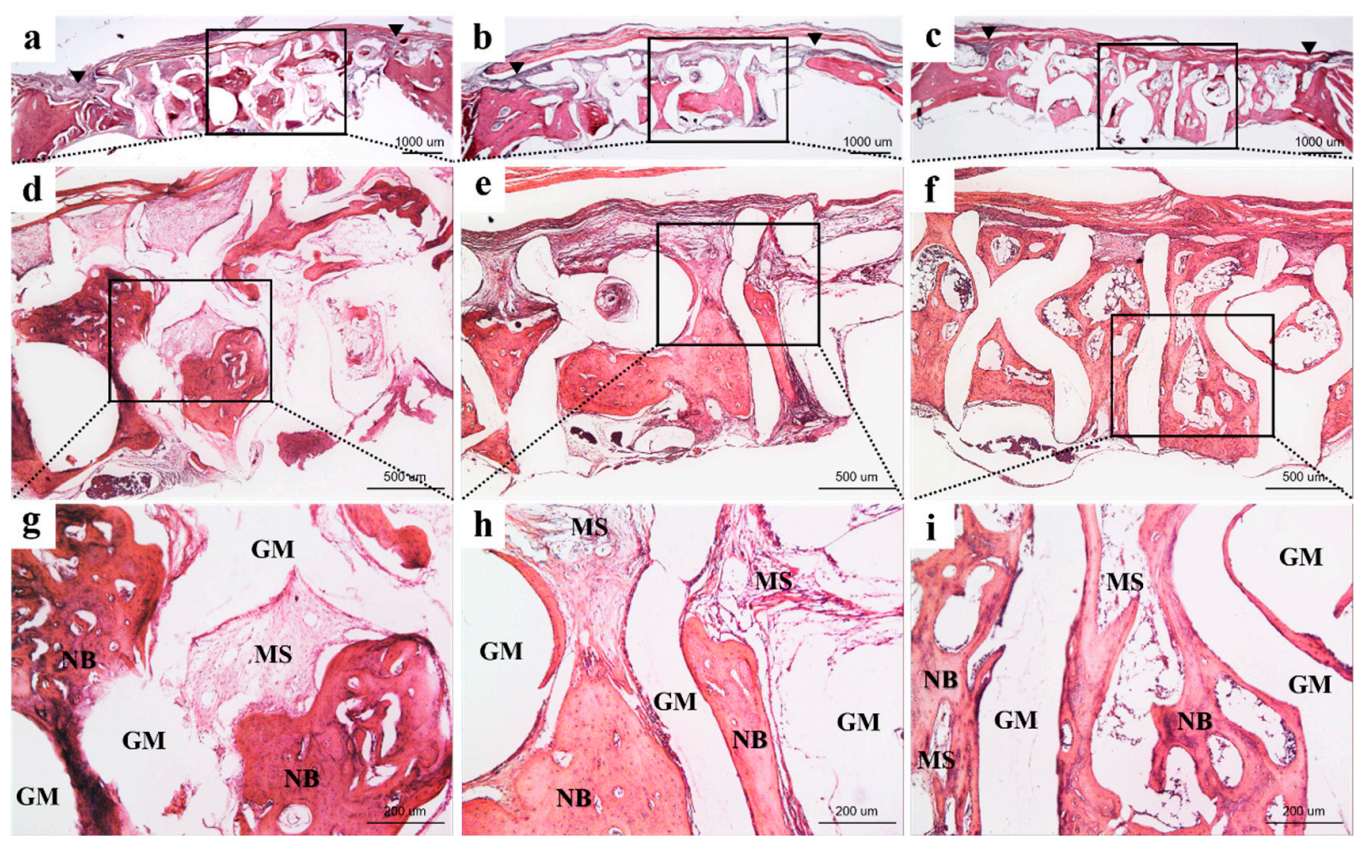

Figure 7. Representative tissue slides at 4-weeks post-surgery: $(\mathbf{a}, \mathbf{d}, \mathbf{g})$ Boneplant; $(\mathbf{b}, \mathbf{e}, \mathbf{h})$ Bonplant/CMC; and $(\mathbf{c}, \mathbf{f}, \mathbf{i})$ Boneplant/CMC/BMP groups. Note: NB = new bone; $\mathrm{MS}=$ marrow space; $\mathrm{GM}=$ bone graft material. Arrow head $=$ margin of defect $(H \& E$ stain, original magnification: $(\mathbf{a}, \mathbf{b}, \mathbf{c}) \times 12.5,(\mathbf{d}, \mathbf{e}, \mathbf{f}) \times 40$, $(\mathbf{g}, \mathbf{h}, \mathbf{i}) \times 100)$.

\subsubsection{Histometric Findings}

The histometric results of measuring the new bone area at 4-weeks post-surgery are shown in Table 2 and Figure 8. The Boneplant/CMC/BMP group exhibited more than two-times more new bone area percentage compared with the other groups, indicating statistically different significance $(P<0.001)$.

Table 2. New bone area percentages within the region of interest ( $n=5$ per group).

\begin{tabular}{lcccc}
\hline & Groups & Mean & SD & $P$-Value \\
\hline \multirow{3}{*}{ New Bone Area (\%) } & Boneplant & 16.48 & 9.11 & \\
& Boneplant/CMC & 16.57 & 8.94 & $0.000^{* * *}$ \\
& Boneplant/CMC/BMP & 33.79 & 3.66 & \\
\hline
\end{tabular}

The symbol ${ }^{* * *}$ indicates statistical significance $(P<0.001)$.

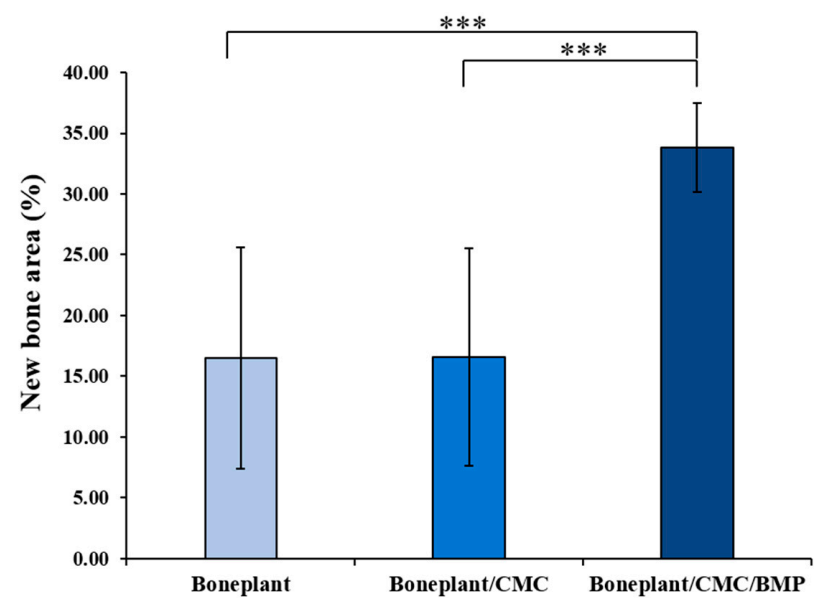

Figure 8. New histometrical bone area percentages of each group. The symbol ${ }^{* * *}$ indicates statistical significance $(P<0.001)$. 


\section{Discussion}

Bone grafting is a difficult task in dental practice, but it is an essential goal to be solved. Various methods and materials for bone grafting have been studied, but finally in this study the focus is on the use of originated bone graft materials in the laboratory, i.e. synthetic bone [47]. Therefore, in this study, we tried to study more stable and predictive bone graft materials and methods by evaluating new bone formation ability using synthetic bone.

Synthetic bone can be made in the form of a block bone, which is advantageous for volume maintenance, and there is no need to worry about additional surgery or lack of bone quantity. In addition, structural morphology, such as porosity, pore size, interconnectivity, and orientation of synthetic bone, affect bone regeneration [48,49]. According to Frame et al. [50], during the alveolar bone augmentation, grafting of compact solid HA alloplastic bone showed less bone formation than that of porous HA alloplastic bone graft. The scaffold-type synthetic bone produced in 3D can be given a variety of internal structures, such as tube, pore, etc. In the pore structure, fluids and nutrients flow into it and circulate [51]. Micropores permit the capture and concentration of proteins that induce differentiation upon contact with undifferentiated cells [52,53]. The pore enables molecular transport necessary for bone regeneration, and an interconnected internal structure increases cell attachment rate [54]. Studies have shown that compared to the convex surface, the concave surface promotes cell attachment and proliferation and is in charge of the initiation of the bone formation process $[52,55]$. The pipe-shaped concave surface in the scaffold used in this study is a favorable form for cell attachment and proliferation. The regular hexahedron is connected with empty pipes and the pipe channels are connected in and out. The blood circulates in and out of the six directions of the pipe structure. Bone materials do not roll down because of the matrix structure of the block, which has a sealing effect when it breaks. When it is pushed, highly reactive surfaces are attached to each other to maintain volume.

Micro CT analysis showed no difference between Boneplant and Boneplant/CMC groups, but Boneplant/CMC/BMP group showed differences in new bone volume production from the other two groups. Boneplant alone showed favorable new bone formation when used alone, but rhBMP-2 using CMC as a carrier showed more bone formation. This was also evident in the area value assessed by histometric finding. The difference between the Boneplant and Boneplant/CMC groups was not found, but the new bone area of Boneplant/CMC/BMP group was twice as large as the other two groups. This suggests that a larger area of new bone was obtained when rhBMP-2 was used, which is consistent with the volume results from the micro CT analysis. This volumetric analysis has the limitation that it could not distinguish the tissues perfectly, but it is considered that a relative comparison could be conducted because we used a single set of equipment and the same analysis level for each tissue in order to distinguish the tissues as clearly as possible.

The use of Boneplant in histological findings was found to be superior to the maintenance of space and volume at defect sites. There was hardly any depression on the superior or inferior sides of the defect site. In all three groups, new bone appeared inside the pore, but Boneplant/CMC/BMP groups were filled with new bone, while Boneplant and Boneplant/CMC groups were found to have more connective tissue around the new bone. The pore size of the scaffolds has been shown to affect nutrient transport during tissue regeneration, as well as cell adhesion and migration $[56,57]$. The appropriate pore size for bone tissue engineering varies slightly depending on conditions, such as 200-400 $\mu \mathrm{m}$ [14], interconnected pore of 300-500 $\mu \mathrm{m}$ [48], 100-300 $\mathrm{m}, 600 \mu \mathrm{m}$ [58], and aligned channel of $270 \mu \mathrm{m}$ [18], and a clear consensus has yet to be reached. However, if the pore is too large, the blood flow is excessive and it is difficult for the cell differentiation to mature, resulting in a lot of fibrous tissue. On the other hand, if the pore is too small, the pore is clogged before the bone regeneration is completed [18]. The pore size of the block bone used in our study ranged from 400 to $700 \mu \mathrm{m}$. Since the channel is not one-way but is six-directional, it is expected that the blood flow was not excessively fast, but it is estimated that some connective tissues were formed inside the pore because of its large pore size. In the Boneplant/CMC/BMP group, rapid differentiation of osteogenic cells was induced by rhBMP-2, 
suggesting less formation of connective tissue and better quality of direct contact in the pores of new bone.

Among the various biomaterials, the ceramics, especially calcium phosphate, have the advantages of mechanical strength, high affinity for proteins, lower degradation rate, and biocompatibility, so this is the most interesting bone substitute nowadays [59]. Kruyt et al. [60] compared the BCP, $\beta$-TCP, and HA with the bone growth ability, and the result showed higher bone growth in BCP and $\beta$-TCP. Lim et al. [61] compared the loading of rhBMP-2 or platelet-rich plasma (PRP) in the $\beta$-TCP scaffold and the bone regeneration effect of rhBMP-2 was much higher. Magne et al. [62] reported that the BCP loaded directly with human growth hormone showed non-constant hormone release, which was rapid in the first 48 hours and slowed down after this. Calcium phosphate can be 3D printed to have pores and this porosity can be a stimulant of osteogenetic behavior. In the previous study, osteogenic and volume abilities were favorable for bone regeneration in BCP block bone having a 3D hexahedron channel structure [44]. In this study, CMC and rhBMP-2 were loaded for faster bone regeneration, and bone maturity and bone mass were significantly increased when rhBMP-2 was added. Releasing a substantial portion of rhBMP-2 and discharging it in a sustained release pattern is helpful for osseointegration and regeneration of the bone defect around the implant [63]. Herford et al. [32] evaluated the effect of rfBMP-2 in the distraction osteogenesis procedure. They concluded that the addition of rhBMP-2 in the distraction osteogenesis technique induces rapid bone regeneration and soft tissue healing in the bone defect site. On the other hand, locally high concentrations due to short half time induce osteoclasts [64]. Therefore, it is important to maintain sustained release at a constant rate using the carrier for release [65]. The effects of diverse delivery systems on growth factors have been studied. In particular, hydrogel [66], collagen sponge [67], and an altered scaffold surface were presented to prolong growth factor release while avoiding primary massive release [68]. In this study, CMC was applied as a carrier for the sustained release. The addition of rhBMP-2 with CMC resulted in a better quality of new bone distribution with less formation of connective tissue in the graft site.

As a limit in this study, firstly, in the animal experiment, the number of the experimental group is the minimum number, and long-term observation could not be performed because it takes time to use large animals and wait to sacrifice them. In animal studies, systematization of overall animal testing, including appropriate drug use and sacrifice timing, customized for each clinical setting will further improve the predictability of animal clinical trials. In addition, rhBMP-2 showed the potential of added autoinducing in this study and proved its potential, but no resolution of carcinogenesis, dosage, long-term results, and suitable carriers has been reported. We did not investigate the kinetic release of the rhBMP-2 in this study and instead referred to the dose concentration used in the previous article [69]. It would be meaningful to measure the releasing profile of rhBMP-2 in the Boneplant/CMC/BMP group, but this study excluded this test because the difference between fast release and slow release of rhBMP-2 was not the main evaluation variable. Eventually, this is the fundamental problem of exposing too much rhBMP-2 to the local area, and additional and continuing research on the appropriate dose and delivery system of rhBMP-2 to biomaterial is needed.

\section{Conclusions}

Bone formation was assessed by grafting using a 3D BCP synthetic block bone with an internal hexahedron channel structure. When the 3D hexahedron channeled BCP block bone was implanted, the volume of the bone was secured to $50 \%$ or more of the transplantation site, and $\mathrm{BCP}$ itself was effective as a transplanted bone at the defect site to maintain volume and produce new bone. The addition of rhBMP-2 with CMC showed significant volume and a large area of new bone. The addition of rhBMP-2 reduced the formation of connective tissue inside the pores and improved the quality of the new bone. Therefore, 3D hexahedron channeled BCP block combined with rhBMP-2 is expected to have a better effect for bone regeneration during bone grafting, and further studies are required for other types of 3D BCP block bone with rhBMP-2. 
Author Contributions: Conceptualization, J.-B.H. and J.-W.H.; formal analysis, E.-B.B. and J.-J.A.; investigation, E.-B.B., J.-J.A., H.-Y.B., and W.-T.C.; data curation, E.-B.B., J.-J.A, H.-Y.B., and W.-T.C.; writing-original draft preparation, S.-Y.K. and E.-B.B.; writing—review and editing, S.-Y.K., J.-W.H., J.-B.H., and E.-B.B.

Acknowledgments: This study was supported by Dental Research Institute (PNUDH DRI-2017-01), Pusan National University Dental Hospital.

Conflicts of Interest: The authors declare no conflict of interest.

\section{References}

1. Javed, F.; Ahmed, H.B.; Crespi, R.; Romanos, G.E. Role of primary stability for successful osseointegration of dental implants: Factors of influence and evaluation. Interv. Med. Appl. Sci. 2013, 5, 162-167. [CrossRef] [PubMed]

2. Del Fabbro, M.; Rosano, G.; Taschieri, S. Implant survival rates after maxillary sinus augmentation. Eur. J. Oral Sci. 2008, 116, 497-506. [CrossRef] [PubMed]

3. Guarino, V.; Causa, F.; Ambrosio, L. Bioactive scaffolds for bone and ligament tissue. Expert Rev. Med Devices 2007, 4, 405-418. [CrossRef] [PubMed]

4. Gultekin, B.A.; Bedeloglu, E.; Kose, T.E.; Mijiritsky, E. Comparison of Bone Resorption Rates after Intraoral Block Bone and Guided Bone Regeneration Augmentation for the Reconstruction of Horizontally Deficient Maxillary Alveolar Ridges. BioMed Res. Int. 2016, 2016, 1-9. [CrossRef] [PubMed]

5. Krasny, M.; Krasny, K.; Fiedor, P.; Zadurska, M.; Kamiński, A. Long-term outcomes of the use of allogeneic, radiation-sterilised bone blocks in reconstruction of the atrophied alveolar ridge in the maxilla and mandible. Cell Tissue Bank. 2015, 16, 631-638. [CrossRef] [PubMed]

6. Le, B.; Borzabadi-Farahani, A.; Nielsen, B. Treatment of labial soft tissue recession around dental implants in the esthetic zone using guided bone regeneration with mineralized allograft: A retrospective clinical case series. J. Oral Maxillofac. Surg. 2016, 74, 1552-1561. [CrossRef] [PubMed]

7. Zhang, X.; Vecchio, K.S. Conversion of natural marine skeletons as scaffolds for bone tissue engineering. Front. Mater. Sci. 2013, 7, 103-117. [CrossRef]

8. Herford, A.S.; Tandon, R.; Stevens, T.W.; Stoffella, E.; Cicciu, M. Immediate distraction osteogenesis: The sandwich technique in combination with rhBMP-2 for anterior maxillary and mandibular defects. J. Craniofacial Surg. 2013, 24, 1383-1387. [CrossRef]

9. Cicciù, M.; Herford, A.; Stoffella, E.; Cervino, G.; Cicciù, D. Protein-Signaled Guided Bone Regeneration Using Titanium Mesh and Rh-BMP2 in Oral Surgery: A Case Report Involving Left Mandibular Reconstruction after Tumor Resection. Open Dent. J. 2012, 6, 51-55. [CrossRef]

10. Athanasiou, V.T.; Papachristou, D.J.; Panagopoulos, A.; Saridis, A.; Scopa, C.D.; Megas, P. Histological comparison of autograft, allograft-DBM, xenograft, and synthetic grafts in a trabecular bone defect: An experimental study in rabbits. Med. Sci. Monit. 2009, 16, BR24-BR31.

11. Dimitriou, R.; Jones, E.; McGonagle, D.; Giannoudis, P.V. Bone regeneration: Current concepts and future directions. BMC Med. 2011, 9, 66. [CrossRef] [PubMed]

12. Asa'Ad, F.; Pagni, G.; Pilipchuk, S.P.; Giannì, A.B.; Giannobile, W.V.; Rasperini, G. 3D-printed scaffolds and biomaterials: Review of alveolar bone augmentation and periodontal regeneration applications. Int. J. Dent. 2016, 2016, 1-15. [CrossRef] [PubMed]

13. Hong, P.; Boyd, D.; Beyea, S.D.; Bezuhly, M. Enhancement of bone consolidation in mandibular distraction osteogenesis: A contemporary review of experimental studies involving adjuvant therapies. J. Plast. Reconstr. Aesthet. Surg. 2013, 66, 883-895. [CrossRef] [PubMed]

14. Shim, J.H.; Moon, T.S.; Yun, M.J.; Jeon, Y.C.; Jeong, C.M.; Cho, D.W.; Huh, J.B. Stimulation of healing within a rabbit calvarial defect by a PCL/PLGA scaffold blended with TCP using solid freeform fabrication technology. J. Mater. Sci. Mater. Med. 2012, 23, 2993-3002. [CrossRef] [PubMed]

15. Lee, M.H.; You, C.; Kim, K.H. Combined effect of a microporous layer and type I collagen coating on a biphasic calcium phosphate scaffold for bone tissue engineering. Materials 2015, 8, 1150-1161. [CrossRef] [PubMed]

16. Kinoshita, Y.; Maeda, H. Recent developments of functional scaffolds for craniomaxillofacial bone tissue engineering applications. Sci. World J. 2013, 2013, 1-21. [CrossRef] 
17. Bružauskaitè, I.; Bironaitè, D.; Bagdonas, E.; Bernotienè, E. Scaffolds and cells for tissue regeneration: Different scaffold pore sizes-different cell effects. Cytotechnology 2016, 68, 355-369. [CrossRef] [PubMed]

18. Seong, Y.J.; Kang, I.G.; Song, E.H.; Kim, H.E.; Jeong, S.H.; Seong, Y.; Kang, I.; Song, E.; Kim, H.; Jeong, S. Calcium phosphate-collagen scaffold with aligned pore channels for enhanced osteochondral regeneration. Adv. Heal. Mater. 2017, 6, 1700966. [CrossRef]

19. Lobo, S.E.; Arinzeh, T.L. Biphasic Calcium Phosphate Ceramics for Bone Regeneration and Tissue Engineering Applications. Materials 2010, 3, 815-826. [CrossRef]

20. Lim, H.C.; Zhang, M.L.; Lee, J.S.; Jung, U.W.; Choi, S.H. Effect of different hydroxyapatite: $\beta$-Tricalcium phosphate ratios on the osteoconductivity of biphasic calcium phosphate in the rabbit sinus model. Int. J. Oral Maxillofac. Implant. 2015, 30, 56-72. [CrossRef]

21. LeGeros, R.Z.; Lin, S.; Rohanizadeh, R.; Mijares, D.; LeGeros, J.P. Biphasic calcium phosphate bioceramics: Preparation, properties and applications. J. Mater. Sci. Mater. Electron. 2003, 14, 201-209. [CrossRef]

22. Herford, A.S.; Lü, M.; Akin, L.; Cicciù, M. Evaluation of a porcine matrix with and without platelet-derived growth factor for bone graft coverage in pigs. Int. J. Oral Maxillofac. Implant. 2012, 27, 1351-1358.

23. Chan, O.; Coathup, M.; Nesbitt, A.; Ho, C.Y.; Hing, K.; Buckland, T.; Campion, C.; Blunn, G. The effects of microporosity on osteoinduction of calcium phosphate bone graft substitute biomaterials. Acta Biomater. 2012, 8, 2788-2794. [CrossRef] [PubMed]

24. Solofomalala, G.D.; Guery, M.; Lesiourd, A.; Le Huec, J.C.; Chauveaux, D.; Laffenetre, O. Bone morphogenetic proteins: From their discoveries till their clinical applications. Eur. J. Orthop. Surg. Traumatol. 2007, 17, 609-615. [CrossRef]

25. Kim, H.C.; Kim, S.N.; Lee, J.Y.; Kim, U.C. Successful strategy of treatment using rhBMP-2 for maxillary sinus graft. J. Korean Dent. Assoc. 2015, 53, 14-27.

26. Liu, S.; Liu, Y.; Jiang, L.; Li, Z.; Lee, S.; Liu, C.; Wang, J.; Zhang, J. Recombinant human BMP-2 accelerates the migration of bone marrow mesenchymal stem cells via the CDC42/PAK1/LIMK1 pathway in vitro and in vivo. Biomater. Sci. 2018, 7, 362-372. [CrossRef] [PubMed]

27. Ikeuchi, M.; Dohi, Y.; Horiuchi, K.; Ohgushi, H.; Noshi, T.; Yoshikawa, T.; Yamamoto, K.; Sugimura, M. Recombinant human bone morphogenetic protein-2 promotes osteogenesis within atelopeptide type I collagen solution by combination with rat cultured marrow cells. J. Biomed. Mater. Res. 2002, 60, 61-69. [CrossRef] [PubMed]

28. Jansen, J.; Vehof, J.; Ruhe, P.; Kroeze-Deutman, H.; Kuboki, Y.; Takita, H.; Hedberg, E.; Mikos, A. Growth factor-loaded scaffolds for bone engineering. J. Controll. Release 2005, 101, 127-136. [CrossRef]

29. Babensee, J.E.; McIntire, L.V.; Mikos, A.G. Growth Factor Delivery for Tissue Engineering. Pharm. Res. 2000, 17, 497-504. [CrossRef]

30. Epstein, N.E. Pros, cons, and costs of INFUSE in spinal surgery. Surg. Neurol. Int. 2011, 2, 10. [CrossRef]

31. Tannoury, C.A.; An, H.S. Complications with the use of bone morphogenetic protein 2 (BMP-2) in spine surgery. Spine J. 2014, 14, 552-559. [CrossRef] [PubMed]

32. Herford, A.S.; Cicciù, M.; Eftimie, L.F.; Miller, M.; Signorino, F.; Famà, F.; Cervino, G.; Lo Giudice, G.; Bramanti, E.; Lauritano, F. rhBMP-2 applied as support of distraction osteogenesis: A split-mouth histological study over nonhuman primates mandibles. Int. J. Clin. Exp. Med. 2016, 9, 17187-17194.

33. Blokhuis, T.J. Formulations and delivery vehicles for bone morphogenetic proteins: Latest advances and future directions. Injury 2009, 40, S8-S11. [CrossRef]

34. Salama, A.; El-Sakhawy, M. Preparation of polyelectrolyte/calcium phosphate hybrids for drug delivery application. Carbohydr. Polym. 2014, 113, 500-506. [CrossRef] [PubMed]

35. Liuyun, J.; Yubao, L.; Chengdong, X. A novel composite membrane of chitosan-carboxymethyl cellulose polyelectrolyte complex membrane filled with nano-hydroxyapatite I. Preparation and properties. J. Mater. Sci. Mater. Med. 2009, 20, 1645-1652. [CrossRef]

36. Stelzer, G.I.; Klug, E. Carboxymethylcellulose. In Handbook of Watersoluble Gums and Resins; McGraw-Hill: New York, NY, USA, 1980; pp. 1-4.

37. Barbucci, R.; Magnani, A.; Consumi, M. swelling behavior of carboxymethylcellulose hydrogels in relation to cross-linking, $\mathrm{pH}$, and charge density. Macromolecules 2000, 33, 7475-7480. [CrossRef]

38. Schweizer, S.; Taubert, A. Polymer-controlled, bio-inspired calcium phosphate mineralization from aqueous solution. Macromol. Biosci. 2007, 7, 1085-1099. [CrossRef] 
39. Salama, A.; Abou-Zeid, R.E.; El-Sakhawy, M.; El-Gendy, A.A. Carboxymethyl cellulose/silica hybrids as templates for calcium phosphate biomimetic mineralization. Int. J. Boil. Macromol. 2015, 74, 155-161. [CrossRef]

40. Santa-Comba, A.; Pereira, A.; Lemos, R.; Santos, D.; Amarante, J.; Pinto, M.; Tavares, P.; Bahia, F. Evaluation of carboxymethylcellulose, hydroxypropylmethylcellulose, and aluminum hydroxide as potential carriers for rhBMP-2. J. Biomed. Mater. Res. 2001, 55, 396-400. [CrossRef]

41. Cook, S.D.; Salkeld, S.L.; Patron, L.P. Bone defect healing with an osteogenic protein-1 device combined with carboxymethylcellulose. J. Biomed. Mater. Res. Part B Appl. Biomater. 2005, 75, 137-145. [CrossRef]

42. Yoo, H.S.; Bae, J.H.; Kim, S.E.; Bae, E.B.; Kim, S.Y.; Choi, K.H.; Moon, K.O.; Jeong, C.M.; Huh, J.B. The effect of bisphasic calcium phosphate block bone graft materials with polysaccharides on bone regeneration. Materials 2017, 10, 17. [CrossRef] [PubMed]

43. Hollister, S.J. Porous scaffold design for tissue engineering. Nat. Mater. 2005, 4, 518-524. [CrossRef] [PubMed]

44. Pae, H.C.; Kang, J.H.; Cha, J.K.; Lee, J.S.; Paik, J.W.; Jung, U.W.; Choi, S.H. Bone regeneration using three-dimensional hexahedron channel structured BCP block in rabbit calvarial defects. J. Biomed. Mater. Res. Part B Appl. Biomater. 2019. [CrossRef] [PubMed]

45. García-Gareta, E.; Coathup, M.J.; Blunn, G.W. Osteoinduction of bone grafting materials for bone repair and regeneration. Bone 2015, 81, 112-121. [CrossRef] [PubMed]

46. Lee, J.H.; Jeong, B. The effect of hyaluronate-carboxymethyl cellulose on bone graft substitute healing in a rat spinal fusion model. J. Korean Neurosurg. Soc. 2011, 50, 409-414. [CrossRef] [PubMed]

47. Cicciù, M.; Cervino, G.; Herford, A.S.; Famà, F.; Bramanti, E.; Fiorillo, L.; Lauritano, F.; Sambataro, S.; Troiano, G.; Laino, L. Facial bone reconstruction using both marine or non-marine bone substitutes: Evaluation of current outcomes in a systematic literature review. Mar. Drugs 2018, 16, 27. [CrossRef] [PubMed]

48. Karageorgiou, V.; Kaplan, D. Porosity of 3D biomaterial scaffolds and osteogenesis. Biomater. 2005, 26, 5474-5491. [CrossRef]

49. Bai, F.; Wang, Z.; Lu, J.; Liu, J.; Chen, G.; Lv, R.; Wang, J.; Lin, K.; Zhang, J.; Huang, X. The Correlation Between the Internal Structure and Vascularization of Controllable Porous Bioceramic Materials In Vivo: A Quantitative Study. Tissue Eng. Part A 2010, 16, 3791-3803. [CrossRef]

50. Frame, J.W.; Rout, P.; Browne, R. Ridge augmentation using solid and porous hydroxylapatite particles with and without autogenous bone or plaster. J. Oral Maxillofac. Surg. 1987, 45, 771-777. [CrossRef]

51. Wei, M.Z.; Da, P.W.; Jian, Y.X. Biological characteristics and clinical application of scaffold materials for bone tissue engineering. J. Clin. Rehabil. Tissue Eng. Res. 2007, 11, 9781.

52. Graziano, A.; d'Aquino, R.; Angelis, M.G.C.D.; De Francesco, F.; Giordano, A.; Laino, G.; Piattelli, A.; Traini, T.; De Rosa, A.; Papaccio, G. Scaffold's surface geometry significantly affects human stem cell bone tissue engineering. J. Cell. Phys. 2008, 214, 166-172. [CrossRef] [PubMed]

53. Ripamonti, U. Osteoinduction in porous hydroxyapatite implanted in heterotopic sites of different animal models. Biomaterials 1996, 17, 31-35. [CrossRef]

54. Lundgren, A.; Sennerby, L.; Lundgren, D. Guided jaw-bone regeneration using an experimental rabbit model. Int. J. Oral Maxillofac. Surg. 1998, 27, 135-140. [CrossRef]

55. Ripamonti, U.; Richter, P.W.; Thomas, M.E. Self-inducing shape memory geometric cues embedded within smart hydroxyapatite-based biomimetic matrices. Plast. Reconstr. Surg. 2007, 120, 1796-1807. [CrossRef] [PubMed]

56. Lien, S.M.; Ko, L.Y.; Huang, T.J. Effect of pore size on ECM secretion and cell growth in gelatin scaffold for articular cartilage tissue engineering. Acta Biomater. 2009, 5, 670-679. [CrossRef] [PubMed]

57. Harley, B.A.; Kim, H.D.; Zaman, M.H.; Yannas, I.V.; Lauffenburger, D.A.; Gibson, L.J. Microarchitecture of three-dimensional scaffolds influences cell migration behavior via junction interactions. Biophys. J. 2008, 95, 4013-4024. [CrossRef] [PubMed]

58. Chiu, Y.C.; Fang, H.Y.; Hsu, T.T.; Lin, C.Y.; Shie, M.Y. The characteristics of mineral trioxide aggregate/ polycaprolactone 3-dimensional scaffold with osteogenesis properties for tissue regeneration. J. Endod. 2017, 43, 923-929. [CrossRef]

59. Agrawal, V.; Sinha, M. A review on carrier systems for bone morphogenetic protein-2. J. Biomed. Mater. Res. Part B Appl. Biomater. 2017, 105, 904-925. [CrossRef] 
60. Kruyt, M.C.; Wilson, C.E.; De Bruijn, J.D.; Van Blitterswijk, C.A.; Oner, C.F.; Verbout, A.J.; Dhert, W.J. The effect of cell-based bone tissue engineering in a goat transverse process model. Biomaterials. 2006, 27, 5099-5106. [CrossRef]

61. Lim, H.P.; Mercado-Pagan, A.E.; Yun, K.D.; Kang, S.S.; Choi, T.H.; Bishop, J.; Koh, J.T.; Maloney, W.; Lee, K.M.; Yang, Y.P. The effect of rhBMP-2 and PRP delivery by biodegradable $\beta$-tricalcium phosphate scaffolds on new bone formation in a non-through rabbit cranial defect model. J. Mater. Sci. Mater. Med. 2013, 24, 1895-1903. [CrossRef]

62. Magne, D.; Bluteau, G.; Lopez-Cazaux, S.; Weiss, P.; Pilet, P.; Ritchie, H.H.; Daculsi, G.; Guicheux, J. Development of an odontoblast in vitro model to study dentin mineralization. Connect. Tissue Res. 2004, 45, 101-108. [CrossRef] [PubMed]

63. Jo, J.H.; Choi, S.W.; Choi, J.W.; Paik, D.H.; Kang, S.S.; Kim, S.E.; Jeon, Y.C.; Huh, J.B. Effects of different rhBMP-2 release profiles in defect areas around dental implants on bone regeneration. Biomed. Mater. 2015, 10, 45007. [CrossRef] [PubMed]

64. Kaneko, H.; Arakawa, T.; Mano, H.; Kaneda, T.; Ogasawara, A.; Nakagawa, M.; Toyama, Y.; Yabe, Y.; Kumegawa, M.; Hakeda, Y. Direct stimulation of osteoclastic bone resorption by bone morphogenetic protein (BMP)-2 and expression of BMP receptors in mature osteoclasts. Bone 2000, 27, 479-486. [CrossRef]

65. Takaoka, K.; Saito, N. New synthetic biodegradable polymers as BMP carriers for bone tissue engineering. Biomaterials 2003, 24, 2287-2293.

66. Fukui, T.; Ii, M.; Shoji, T.; Matsumoto, T.; Mifune, Y.; Kawakami, Y.; Akimaru, H.; Kawamoto, A.; Kuroda, T.; Saito, T.; et al. Therapeutic effect of local administration of low-dose simvastatin-conjugated gelatin hydrogel for fracture healing. J. Bone Miner. Res. 2012, 27, 1118-1131. [CrossRef] [PubMed]

67. Monjo, M.; Rubert, M.; Wohlfahrt, J.C.; Rønold, H.J.; Ellingsen, J.E.; Lyngstadaas, S.P. In vivo performance of absorbable collagen sponges with rosuvastatin in critical-size cortical bone defects. Acta Biomater. 2010, 6, 1405-1412. [CrossRef]

68. Walter, M.S.; Frank, M.J.; Rubert, M.; Monjo, M.; Lyngstadaas, S.P.; Haugen, H.J. Simvastatin-activated implant surface promotes osteoblast differentiation in vitro. J. Biomater. Appl. 2014, 28, 897-908. [CrossRef]

69. Park, J.C.; Bae, E.B.; Kim, S.E.; Kim, S.Y.; Choi, K.H.; Choi, J.W.; Bae, J.H.; Ryu, J.J.; Huh, J.B. Effects of BMP-2 delivery in calcium phosphate bone graft materials with different compositions on bone regeneration. Materials 2016, 9, 954. [CrossRef] 